\title{
Antioxidant protection and PSII regulation mitigate photo-oxidative stress induced by drought followed by high light in cashew plants
}

\author{
Cristina Silva Lima ${ }^{\mathrm{a}, 1}$, Sérgio Luiz Ferreira-Silva ${ }^{\mathrm{b}, 1}$, Fabricio Eulálio Leite Carvalho ${ }^{\mathrm{a}}$, \\ Milton Costa Lima Neto ${ }^{c}$, Rafael Magalhães Aragão ${ }^{\mathrm{d}}$, Evandro Nascimento Silva ${ }^{\mathrm{e}}$, \\ Raysa Mayara J. Sousa ${ }^{a}$, Joaquim Albenisio Gomes Silveira ${ }^{a, *}$ \\ a Department of Biochemistry and Molecular Biology, Federal University of Ceará, Fortaleza, Ceará, Brazil \\ ${ }^{\mathrm{b}}$ Postgraduate Program in Plant Production, Serra Talhada Academic Unit, Federal Rural University of Pernambuco, Serra Talhada, Pernambuco, Brazil \\ ${ }^{\mathrm{c}}$ State University of São Paulo, Experimental Campus of São Paulo Coast, UNESP-CLP, São Vicente, São Paulo, Brazil \\ ${ }^{\mathrm{d}}$ Federal Rural University of Amazonia, UFRA, Capanema Campus, Capanema, Pará, Brazil \\ e State University of Ceara, Faculty of Education, Sciences and Letters of Central Sertão, Quixadá, Ceará, Brazil
}

\section{A R T I C L E I N F O}

\section{Keywords:}

Anacardium occidentale

Excess energy

NPQ

Photosynthesis

Water deficit

\begin{abstract}
A B S T R A C T
We tested the hypothesis that effective antioxidant and photoprotective mechanisms are able to avoid photodamage induced by prolonged water deficit (WD) followed by high light (HL). We employed cashew plants (Anacardium occidentale L.), a semiarid adapted species, as a model plant. WD-plants exposed to HL did not show alterations in maximum quantum efficiency of photosystem II (Fv/Fm), cellular integrity, $\mathrm{H}_{2} \mathrm{O}_{2}$ and thiobarbituric acid reactive species (TBARS) contents, evidencing that they did not suffered photoinhibition and oxidative stress. These responses were associated with increases in ascorbate peroxidase (APX) and superoxide dismutase (SOD) activities, glutathione (GSH) oxidation and ascorbate (ASC) synthesis. This effective oxidative protection occurred in parallel to strong decrease in photosystem II and I (PSII and PSI) activities, increase in heat dissipation ( $\mathrm{qE}$ ), which was related to enhancement in cyclic electron flux. These favorable photoprotective changes were associated with efficient water use in response to HL, all contributing to avoid excess energy in chloroplasts of drought-exposed leaves. These protective features were associated with a tight regulation in D1 protein accumulation during HL, contributing to avoid reactive oxygen species over-accumulation and a subsequent effective PSII recovery during darkness. Our results indicate that cashew plants are able to avoid photoinhibition, tolerating extreme conditions of drought combined with HL. The displayed mechanisms involve essentially integrated responses to balance energy input and output, avoiding oxidative stress.
\end{abstract}

\section{Introduction}

Abiotic stress in tropical semiarid regions involves diverse limiting factors for plant growth and development, such as drought, salinity, heat and excessive light. In such regions these constraints generally persist for a long time during the year, affecting severely plant growth and survival. Plants highly adapted to these conditions have developed specific mechanisms of acclimation that are associated with maintaining photosynthetic capacity (Adams et al., 2013; Demmig-Adams et al., 2017, 2015). Some of these evergreen species can trigger acclimation mechanisms when exposed simultaneously to water deficit (WD) and high light (HL) (Suzuki et al., 2014). These strategies involve a more efficient water use (Flexas et al., 2013), maintaining high $\mathrm{CO}_{2}$ assimilation under low stomatal aperture (Galmés et al., 2013, 2006) and triggering several other photoprotective mechanisms (Suzuki et al., 2014).

These conspicuous mechanisms might allow semiarid adapted plants to grow under extreme environmental conditions, where other species would not survive (Adams et al., 2013; Demmig-Adams et al., 2017, 2015). Numerous mechanisms related to plant defense against

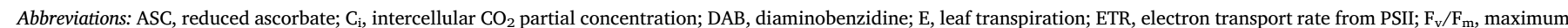

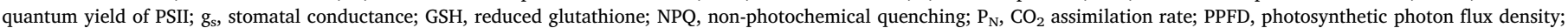

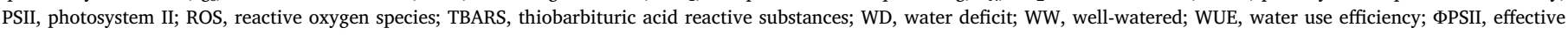
quantum yield of PSII; ФPSI, effective quantum yield of PSI

* Corresponding author at: Departamento de Bioquímica e Biologia Molecular, Laboratório de Metabolismo de Plantas, Universidade Federal do Ceará. Av. Humberto Monte 2825, Campus do Pici, Bl. 907. Fortaleza, CP 6020, CEP 60451-970, Ceará, Brazil.

E-mail address: silveira@ufc.br (J.A.G. Silveira).

${ }^{1}$ These authors contributed equally to the manuscript. 
high light and water deficit are widely known, especially in model plants such as Arabidopsis thaliana (Suzuki et al., 2014). However, the mechanisms that confer tolerance to extreme environmental conditions remain poorly understood, particularly in species adapted to semiarid regions (Silveira and Carvalho, 2016). The knowledge of such physiological mechanisms is important because it might contribute to improvement of cultivated non-adapted species through genetic transference of new tolerance genes (Silveira and Carvalho, 2016).

Drought-tolerant plants respond to water stress primarily through the fine control of stomatal and mesophyll conductance (Pinheiro and Chaves, 2011). Nevertheless, under these conditions, impairments of $\mathrm{CO}_{2}$ assimilation as well as restrictions in growth and metabolism are common (Flexas et al., 2002; Pinheiro and Chaves, 2011; Zou et al., 2015). Under these photosynthetically restrictive conditions, imbalances between light capture, photochemical activity and energy utilization by biochemical processes, especially Calvin-Benson cycle reactions, generally emerge (Silveira and Carvalho, 2016). These unbalanced circumstances might lead to excessive generation of reactive oxygen species (ROS), which can cause oxidative damage to photosynthetic components (Foyer et al., 2012; Silveira and Carvalho, 2016).

It has been amply reported that excessive ROS delay the turnover of D1 protein in the PSII core, thereby contributing to its inactivation, a process referred to as photoinhibition (Nishiyama et al., 2011). Under stressful conditions, this process can be rendered transient by maintaining D1 re-synthesis and avoiding photoinhibition and permanent damage to PSII (Tikkanen and Aro, 2014). In chloroplasts, the local isoforms of superoxide dismutase (SOD) and ascorbate peroxidase (APX) are crucial to controlling excessive levels of superoxide and $\mathrm{H}_{2} \mathrm{O}_{2}$. In addition, these antioxidant enzymes contribute to energy dissipation via the water-water cycle (Asada, 1992; Shigeoka and Maruta, 2014).

Other important photochemical processes related to photoprotection include a) reduction in light capture through the decrease in amount of antenna components and b) excess energy dissipation via thermal component of non-photochemical quenching ( $\mathrm{qE}$ ), which is dependent on the thylakoid $\Delta \mathrm{pH}$, the amount of PsbS protein and the zeaxanthin-violaxanthin balance via violaxanthin de-epoxidase activity (Ruban, 2017). In addition, the equilibrium between the photochemical activities of PSII and PSI and the regulation of cyclic electron flow are also very important as photoprotective mechanisms (Finazzi and Johnson, 2016; Labs et al., 2016).

Cashew (Anacardium occidentale) is a tropical evergreen tree widely cultivated in Brazilian semiarid coastal regions and is currently an economically important crop in Brazil, India and East Africa (de Souza et al., 2005; Ferreira-Silva et al., 2012, 2011, 2010, 2008). This species has developed genetic, molecular and physiological mechanisms to overcome adverse conditions such as salinity, drought and high temperature (Baker and Rosenqvist, 2004; Blaikie and Chacko, 1998; Ferreira-Silva et al., 2011, 2010). Recently, we demonstrated that high temperature is required to up-regulate oxidative defense in cashew leaves subjected to salt stress (Ferreira-Silva et al., 2011), which suggests that this species is adapted to cope with combined stresses, which are common in semiarid regions.

Here, we tested the hypothesis that species naturally adapted to cope with chronic water deficit combined with high light display effective photoprotective mechanisms to avoid photo-oxidative stress. The results demonstrate that cashew plants under these conditions were able to trigger several protective mechanisms, highlighting a powerful antioxidant system. The low ROS levels illustrate that drought-exposed plants have a more effective PSII recovery during dark, possibly suggesting a more efficient D1 turnover. In addition, these plants were able to improve their $\mathrm{CO}_{2}$ assimilation rates, contributing, in turn, for attenuation of ROS accumulation in photosystems. The importance of such mechanisms for acclimation to combined effects of drought followed by high light is discussed.

\section{Materials and methods}

\subsection{Plant material, growth and drought experiment}

Cashew seeds (Anacardium occidentale L.) of the CCP 06 genotype were provided by EMBRAPA, Brazil. Seeds were surface-disinfected with $5 \%(\mathrm{w} / \mathrm{v})$ sodium hypochlorite, washed in distilled water and sown in vermiculite (medium texture, $0.12 \mathrm{~g} / \mathrm{cm}^{3}$ density and $100 \%$ $(\mathrm{m} / \mathrm{m})$ of water holding capacity for saturation) in $3 \mathrm{~L}$ plastic pots. The substrate water content was maintained at $100 \%$ of the vermiculite holding capacity by irrigation with quarter-strength Hoagland and Arnon's nutrient solution. Plants were initially grown in a greenhouse under natural conditions with average temperature of $29^{\circ} \mathrm{C}$ (day) $/ 25^{\circ} \mathrm{C}$ (night), average relative humidity of $62 \%$ (day) $/ 82 \%$ (night), and natural sunlight with an average maximum photosynthetic photon flux density (PPFD) of $850 \mu \mathrm{mol} \mathrm{m}{ }^{-2} \mathrm{~s}^{-1}$ and a photoperiod of $12 \mathrm{~h}$. At 35 days old, plants were separated into two groups: (1) well-watered WW and (2) water deficit (WD), which were exposed to 21 days of water withdrawal. In order to characterize the water deficit intensity, the following indicators were measured every five days: transpiration, leaf relative water content and substrate water content. Subsequently, 55-day-old plants (at the stage of eight fully expanded leaves) were utilized for the biochemical and physiological measurements.

\subsection{Experiments in controlled growth chamber}

In order to perform controlled light experiments, the plants were transferred from greenhouse to a controlled growth chamber. The plants were acclimated to the chamber conditions for 3 days before performing the experiments. The growth chamber was set to the following conditions: day/night temperature of $29^{\circ} \mathrm{C} \pm 3{ }^{\circ} \mathrm{C} /$ $24{ }^{\circ} \mathrm{C} \pm 1{ }^{\circ} \mathrm{C}$ and relative humidity $58 \% \pm 9 \%$ and continuous light intensity of $400 \mu \mathrm{mol}$ photons $\mathrm{m}^{-2} \mathrm{~s}^{-1}$ for $12 \mathrm{~h}$ photoperiods, supplied by a combination of fluorescent $(30 \mathrm{~W})$ and high-pressure sodium vapor (400 W) lamps.

\subsection{Gas exchange determinations}

Photosynthetic $\mathrm{CO}_{2}$ assimilation $\left(\mathrm{P}_{\mathrm{N}}\right)$, stomatal conductance $\left(\mathrm{g}_{\mathrm{s}}\right)$ and transpiration $(E)$ were measured in fully expanded leaves from cashew plants with a portable infrared gas analyzer system equipped with an LED source and a leaf chamber (IRGA LI-6400XT, LI-COR, Lincoln, USA). The internal parameters inside IRGA chamber during gas exchange measurements were $1000 \mu \mathrm{mol} \mathrm{m}^{-2} \mathrm{~s}^{-1}$ PPFD, $1.0 \pm 0.2 \mathrm{kPa}$ VPD and $38 \mathrm{~Pa} \mathrm{CO}_{2}$ and $28^{\circ} \mathrm{C}$. Blue light amount was set to $10 \%$ of the PPFD to maximize stomatal aperture (Flexas et al., 2008). Water use efficiency (WUE) was calculated as $\mathrm{P}_{\mathrm{N}} / \mathrm{E}$.

\subsection{Short- and long-term PSII kinetics and PSI activity determinations}

The PSII parameters of maximum $[\mathrm{Fv} / \mathrm{Fm}=(\mathrm{Fm}-\mathrm{Fo}) / \mathrm{Fm}]$ and actual quantum efficiency [ФPSII $=$ Fm'-Fs/Fm'], non-photochemical quenching $[\mathrm{NPQ}=(\mathrm{Fm} / \mathrm{Fm}$ ')-1] and redox state of quinones $[1-\mathrm{qP}=1$ (Fm'-Fs)/(Fm'-Fo')] were quantified in fully expanded cashew leaves using a Dual-PAM 100 (Walz, Germany) and a LI-6400-40 fluorimeter (LI-COR, Lincoln, NE, USA) coupled to an IRGA equipment. For the short-term PSII kinetics, leaves form WW and WD cashew plants were dark adapted for $30 \mathrm{~min}$ and a saturation pulse ( $\mathrm{SP}=8000 \mu \mathrm{mol} \mathrm{m}{ }^{-2} \mathrm{~s}^{-1}$; by $0.6 \mathrm{~s}$ ) was supplied to obtain $\mathrm{Fm}$ values (Schreiber et al., 1995). Subsequently, leaves were illuminated by an actinic light $\left(2000 \mu \mathrm{mol} \mathrm{m}{ }^{-2} \mathrm{~s}^{-1}\right)$ for $30 \mathrm{~min}$ and similar SP were performed every $30 \mathrm{~s}$, to access Fm' values. For recovery, similar SPs were employed within different time intervals, during $1 \mathrm{~h}$ in the dark. For the long-term PSII kinetics, the Fm values were obtained by a similar SP $\left(8000 \mu \mathrm{mol} \mathrm{m}^{-2} \mathrm{~s}^{-1}\right.$; by $\left.0.6 \mathrm{~s}\right)$ performed in pre-dawn dark-adapted leaves. Leaves were subsequently exposed to an actinic light 
$\left(2000 \mu \mathrm{mol} \mathrm{m}^{-2} \mathrm{~s}^{-1}\right)$ for $12 \mathrm{~h}$. A similar SP was performed at 3, 4, 5, 6, 9 and $12 \mathrm{~h}$ after light exposure for estimation of Fm'.

PSI photochemical measurements were performed in a DUAL-PAM 100 (Walz, Effeltrich, Germany). The following parameters of PSI were

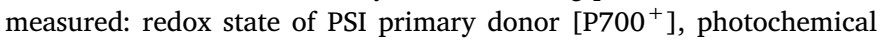
quantum yield of PSI [ФPSI $=1-\mathrm{Y}(\mathrm{ND})-\mathrm{Y}(\mathrm{NA})$ ] as described previously by Klughammer and Schreiber (1994). Y(ND) and Y(NA) are, respectively, non-photochemical quantum yield at donor side of PSI [Y $(\mathrm{ND})=1-\mathrm{P700}$ reduced] and non-photochemical quantum yield at acceptor side of PSI $[\mathrm{Y}(\mathrm{NA})=(\mathrm{Pm}-\mathrm{Pm}) / \mathrm{Pm}]$. Cyclic electron flux was estimated as ETRI/ETRII, as described previously by Yamori et al. (2011).

\subsection{Western blotting}

Proteins $(20 \mu \mathrm{g})$ were first separated by SDS-PAGE and subsequently they were electrophoretically transferred to a nitrocellulose membrane as described by Towbin et al. (1979). Subsequently, the membrane was blocked overnight with $5 \%(\mathrm{~m} / \mathrm{v})$ non-fat milk in $100 \mathrm{mM}$ Tris- $\mathrm{HCl}$ buffer, pH 7.6, containing $150 \mathrm{mM} \mathrm{NaCl}$, and $0.05 \%$ Tween-20 and incubated with primary polyclonal antibodies against D1, plastocyanin and catalase (Agrisera $\subseteq$, Sweden). Specific polypeptides were revealed after incubation with the secondary antibodies conjugated with peroxidase (Agrisera $($, Sweden). ECL plus Western Blotting Detection System $^{\bullet}$ was used for detection (GE Healthcare Life Sciences@), UK), according to manufacturer's instructions.

\subsection{Hydrogen peroxide, membrane damage and lipid peroxidation determinations}

Hydrogen peroxide was measured according to the methods described by Cheeseman (2006). Samples of fresh leaves $(0.1 \mathrm{~g})$ were powdered in liquid $\mathrm{N}_{2}$ and extracted in $100 \mathrm{mM}$ potassium phosphate buffer (pH 6.4) containing $5 \mathrm{mM} \mathrm{KCN}$. Reaction was performed at $25^{\circ} \mathrm{C}$ for $30 \mathrm{~min}$, and absorbance was read at $560 \mathrm{\eta m}$. Hydrogen peroxide concentration was expressed as $\mu \mathrm{mol} \mathrm{g}^{-1}$ FW. In situ $\mathrm{H}_{2} \mathrm{O}_{2}$ accumulation was performed by staining with $3,3^{\prime}$ - diaminobenzidine (DAB) as described by Lin et al. (2013). Whole leaves were vacuum infiltrated under dark conditions with a $0.1 \%(\mathrm{w} / \mathrm{v})$ DAB solution for $15 \mathrm{~min}$. Leaves were incubated for approximately $16 \mathrm{~h}$ in dark conditions and then depigmented with $0.15 \%(\mathrm{w} / \mathrm{v})$ trichloroacetic acid in an ethanol/ chloroform solution $(4: 1 \mathrm{v} / \mathrm{v})$ for $48 \mathrm{~h}$ before being photographed. Leaf membrane damage was estimated based on leaf $\mathrm{K}^{+}$leakage and leaf relative water content (RWC) were determined as previously described by Cavalcanti et al. (2004). Lipid peroxidation was measured based on formation of thiobarbituric acid-reactive substances (TBARS) in accordance with Cakmak and Horst (1991) and results were expressed as ๆmol MDA-TBA $\mathrm{g}^{-1} \mathrm{FW}$.

\subsection{Determination of ascorbate and glutathione redox states}

The ascorbate content was assayed according to Kampfenkel et al. (1995). The assay is based on the reduction of $\mathrm{Fe}^{3+}$ to $\mathrm{Fe}^{2+}$ by reduced ascorbate (ASC) and the spectrophotometric detection of $\mathrm{Fe}^{2+}$ complexed with 2,2'-bipyridyl, giving a pink color. The leaf samples $(0.1 \mathrm{~g}$ FW) were homogenized in cold $6 \%$ trichloroacetic acid (TCA) (w/v), the homogenate was centrifuged at $12,000 \mathrm{~g}\left(4^{\circ} \mathrm{C}\right)$ for $20 \mathrm{~min}$. The total ascorbate (ASC + DHA) was measured after a complete reduction of the oxidized fraction by the reaction of the samples with dithiothreitol (DTT) in excess $(10 \mathrm{mM})$. Subsequently, the remaining DTT was removed by $0.5 \%(\mathrm{~m} / \mathrm{v}) \mathrm{N}$-ethylmaleimide, and the DHA was calculated as the difference between total ascorbate and reduced ASC. Ascorbate was expressed as $\mu \mathrm{mol}$ ASC $\mathrm{g}^{-1}$ fresh weight (F.W.). The glutathione (GSH) was measured by the glutathione reductase (GR)-dependent reduction of 5,5'-dithiobis (2-nitro-benzoic acid), DTNB, according to Griffith (1980). Total glutathione content [oxidized glutathione
(GSSG)] was assayed with reaction medium containing 1.0 unit of glutathione reductase, $0.15 \mathrm{~mm} \mathrm{NADPH}, 100 \mathrm{~mm}$ sodium phosphate buffer ( $\mathrm{pH}$ 7.0) and $30 \mathrm{~mm}$ DTNB. Subsequently, the absorbance was read at $412 \mathrm{~nm}$. To estimate total glutathione $2 \% 2$-vinylpyridine was added to the extracts in order to derivatize total GSH into GSSG form. The GSSG was therefore determined as the difference between total glutathione (derivatized) and initial GSH (non-derivatized). Glutathione was expressed as $\mu \mathrm{mol} \mathrm{GSH} \mathrm{g}^{-1}$ fresh weight (FW).

\subsection{Enzymatic assays}

Protein extraction for enzymatic assays was performed as previously described by Zimmermann et al. (2006). In extraction medium, $2 \mathrm{mM}$ ascorbate was added to avoid APX denaturation. Superoxide dismutase (SOD; EC: 1.15.1.1) activity was determined by adding leaf extract to a mixture containing $50 \mathrm{mM}$ potassium phosphate buffer ( $\mathrm{pH} 7.8$ ), $0.1 \mathrm{mM}$ EDTA, $13 \mathrm{mM}$ L-methionine, $2 \mu \mathrm{M}$ riboflavin, and $75 \mu \mathrm{M} p$-nitro blue tetrazolium chloride (NBT) in under darkness. The reaction was performed under illumination (30W fluorescent lamp) at $25^{\circ} \mathrm{C}$ for $6 \mathrm{~min}$. Absorbance was measured at $540 \mathrm{\eta m}$ (Giannopolitis and Ries, 1977). One SOD activity unit (AU) was defined as the amount of enzyme required to inhibit NBT photoreduction by $50 \%$ (Beauchamp and Fridovich, 1971), and activity was expressed as $\mathrm{AU} \mathrm{g}^{-1} \mathrm{FW} \mathrm{min}^{-1}$. Ascorbate peroxidases (APX; EC: 1.11.1.11) activity was assayed after reaction in presence of $50 \mathrm{mM}$ potassium phosphate buffer ( $\mathrm{pH}$ 6.0) and $0.5 \mathrm{mM}$ ascorbic acid and enzymatic extract. Reaction started when $0.1 \mathrm{~mL}$ of $30 \mathrm{mM} \mathrm{H}_{2} \mathrm{O}_{2}$ was added, and the decreasing absorbance at $290 \eta \mathrm{m}$ was monitored over $300 \mathrm{~s}$ (Nakano and Asada, 1981). APX activity was estimated by utilizing the molar extinction coefficient of ascorbate $\left(2.8 \mathrm{mM}^{-1} \mathrm{~cm}^{-1}\right)$ and expressed as $\mu \mathrm{mol} \mathrm{AsA} \mathrm{g}^{-1} \mathrm{FW} \mathrm{min}{ }^{-1}$. Catalase (EC: 1.11.1.6) activity was determined after reaction of enzymatic extract in presence of $50 \mathrm{mM}$ potassium phosphate buffer $(\mathrm{pH}$ 7.0) containing $20 \mathrm{mM} \mathrm{H}_{2} \mathrm{O}_{2}$. The reaction took place at $30^{\circ} \mathrm{C}$, monitoring the absorbance at $240 \eta \mathrm{m}$ over $300 \mathrm{~s}$ (Havir et al., 1987). CAT activity was calculated according to the molar extinction coefficient of $\mathrm{H}_{2} \mathrm{O}_{2}\left(36 \mathrm{M}^{-1} \mathrm{~cm}^{-1}\right)$ and was expressed as $\mu \mathrm{mol} \mathrm{H}_{2} \mathrm{O}_{2} \mathrm{~g}^{-1} \mathrm{FW} \mathrm{min}{ }^{-1}$.

\subsection{Statistical analysis}

All experiments were performed employing a completely randomized design. In each experiment four biological replicates were utilized and each replicate consisted of a 3L pot containing an individual plant. Data were analyzed by ANOVA and means were compared by Tukey's test at a 0.05 significance probability level ( $\mathrm{p} \leq 0.05)$.

\section{Results}

\subsection{Extended water deficit did not induce oxidative stress in cashew plants}

Cashew plants were exposed to gradual WD for 21 consecutive days, in a greenhouse presenting high vapor pressure deficit in order to induce water deficit. After that, WD-plants showed significant decrease in shoot size and leaf area, compared to well-watered control (Fig. S1). However, leaves did not exhibit any injury symptoms, as revealed by unchanged values of relative water content and membrane damage (Table S1). These responses were corroborated by leaf visual aspect, which did not exhibit any visual symptoms of dehydration, senescence or necrosis (Fig. S1). WD-plants presented a marked reduction in transpiration, which dropped to $5 \%$ of that observed in WW. The soil water content decreased abruptly after five days of water withdrawal, but afterwards it declined gradually (Table S1). At the end of the experimental period, the gravimetric water content dropped to $17 \%$ compared to control. This humidity value corresponded to approximately $50 \mathrm{~mL}$ of water per pot, which indicates very low water availability for roots, especially considering a substrate with high water holding capacity like vermiculite. 

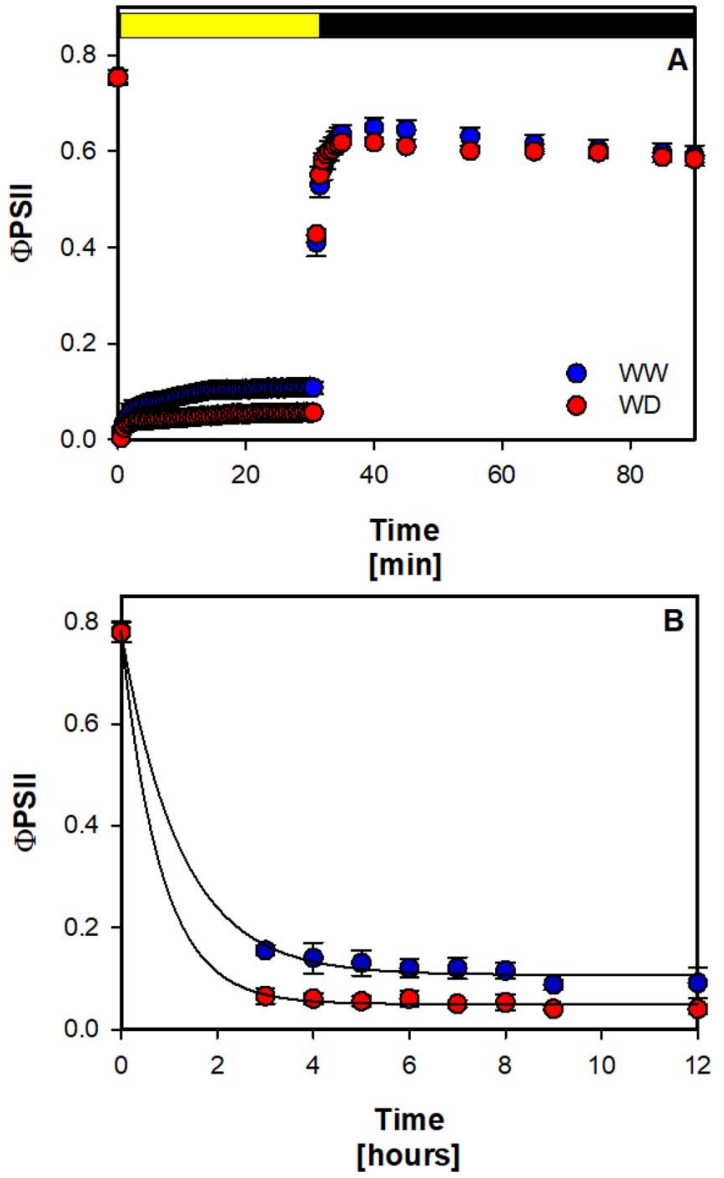

Fig. 1. Short- and long-term kinetics of PSII actual quantum efficiency (ФPSII) measured in leaves from cashew plants exposed to different watering conditions, well-watered (WW, blue circles) and water-deficit (WD, red circles) for 21 days. (A) Short-term kinetics were measured on leaves by exposition to actinic light $(2000 \mu \mathrm{mol} \mathrm{m}-2 \mathrm{~s}-1)$ for $30 \mathrm{~min}$, followed by dark relaxation for $1 \mathrm{~h}$. (B) Long-term kinetics were measured on leaves by whole plant exposition to constant HL $(2000 \mu \mathrm{mol} \mathrm{m}-2 \mathrm{~s}-1)$ and determinations were performed at 3, 4, 5, 6, 7, 8, 9 and $12 \mathrm{~h}$ after pre-dawn. Circles are average of three independent measurements performed in independent plants $(n=3)$ and bars represent the standard error. (For interpretation of the references to colour in this figure legend, the reader is referred to the web version of this article.)

\subsection{WD cashew plants exhibited an efficient decrease in PSII activity in response to high light}

To investigate contrasting photoprotection mechanisms in WD and WW cashew plants were exposed to HL. Both plants show similar Fv/ Fm values at darkness (Fig. 1A). After light induction $(30 \mathrm{~min})$, the actual photochemical yield of PSII ( creased more markedly (by 50\%) as compared to WW leaves. However, despite lower $\Phi P S I I$ in the light, WD plants displayed a faster recovery in this photochemical parameter, reaching values similar to that showed by WW plants after the first minutes of dark relaxation, possibly indicating a more efficient recovery in PSII activity (Fig. 1A). The decrease in PSII activity in WD plants, in comparison to WW, was corroborated by long-term HL experiments, where WD plants exhibited ФPSII values $50 \%$ lower than WW plants during $12 \mathrm{~h}$ of HL exposure (Fig. 1B).

Corroborating the previous described results for ФPSII, WD plants displayed a significant decrease (by 20\%) in the initial slope for ETRII formation ( $\alpha$ value) as compared to WW plants. Those plants also exhibited a strong decrease in maximum ETRII, which varied from $88 \mu \mathrm{mol} \mathrm{m}^{-2} \mathrm{~s}^{-1}$ in WW plants to $42 \mu \mathrm{mol} \mathrm{m}^{-2} \mathrm{~s}^{-1}$ in WD plants (Fig. 2A). The ETRII response to long-term HL exposure also evidenced the decreased capacity of electron transport rate from PSII in leaves
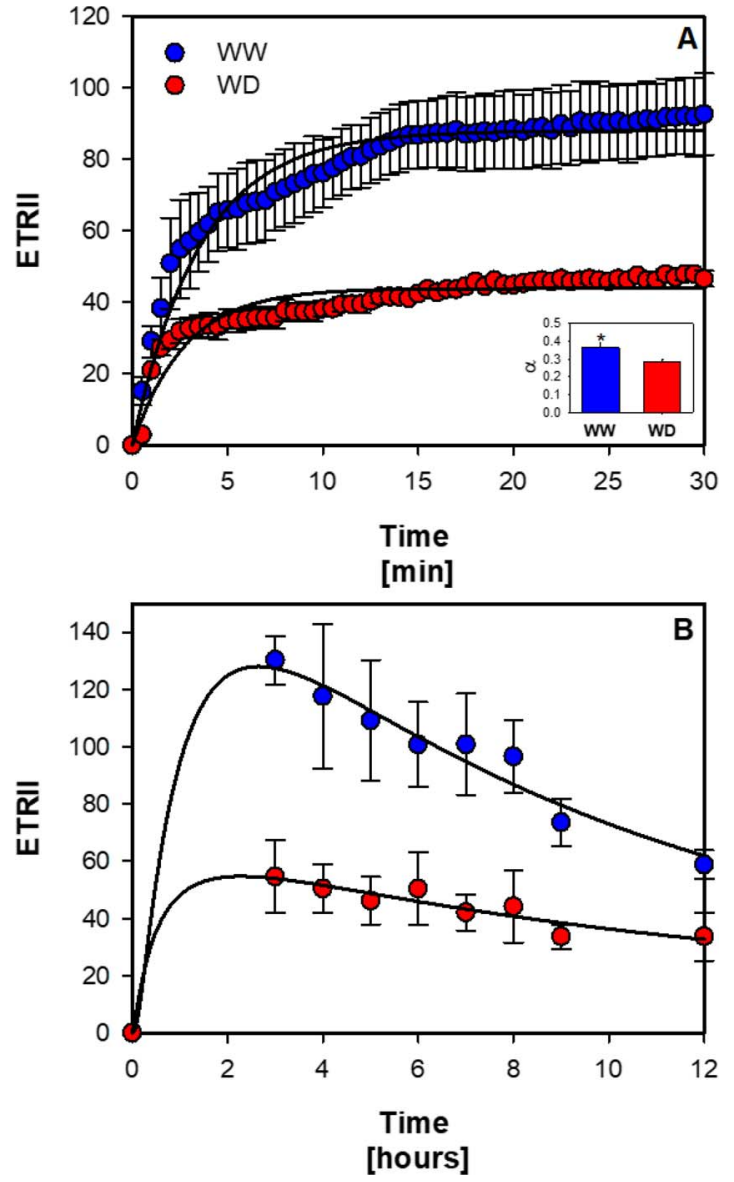

Fig. 2. Short- and long-term kinetics of PSII electron transport ratio (ETRII) measured in leaves from cashew plants exposed to different watering conditions, well-watered (WW, blue circles) and water-deficit (WD, red circles) for 21 days. (A) Short-term kinetics were measured on leaves by exposition to actinic light $\left(2000 \mu \mathrm{mol} \mathrm{m}^{-2} \mathrm{~s}^{-1}\right)$ for $30 \mathrm{~min}$, followed by dark relaxation for $1 \mathrm{~h}$. (B) Long-term kinetics were measured on leaves by whole plant exposition to constant $\mathrm{HL}\left(2000 \mu \mathrm{mol} \mathrm{m}^{-2} \mathrm{~s}^{-1}\right)$ and determinations were performed at $3,4,5,6,7,8,9$ and $12 \mathrm{~h}$ after pre-dawn. Circles are average of three independent measurements performed in independent plants $(\mathrm{n}=3)$ and bars represent the standard error. (For interpretation of the references to colour in this figure legend, the reader is referred to the web version of this article.)

from WD plants (Fig. 2B). Interestingly, the D1 protein amounts in cashew plants revealed that the decreased activity of PSII exhibited by WD plants was related to the decrease in this protein amount (Fig. 3). In WW plants, the D1 amounts decreased progressively from 3 to $12 \mathrm{~h}$ of HL exposure (Fig. 3). Otherwise, WD plants already exhibited very low amounts of D1 protein after $3 \mathrm{~h}$ of HL exposure (Fig. 3). Interestingly, at $3 \mathrm{~h}$ of HL exposure, WD plants did not exhibited differences in plastocyanin amount in comparison to WW (Fig. 3). Subsequently, at 6 and $12 \mathrm{~h}$ HL exposure, WD plants exhibited a decrease in plastocyanin content but no changes in this protein amount was detected in WW plants (Fig. 3).

\subsection{WD cashew plants are capable to trigger a higher and faster NPQ induction as compared to WW plants}

The non-photochemical quenching (NPQ) in WD plants was more intensely induced (approximately $40 \%$ ) in response to $\mathrm{HL}$ (30 $\mathrm{min}$ ) as compared to WW plants (Fig. 4A). This increase in maximum NPQ was accompanied by a prominent increase in the initial slope for NPQ formation ( $\alpha$ value) that significantly varied from 0.2 in WW plants to 0.4 in WD exposed leaves (Fig. 4A). During dark relaxation, NPQ rapidly decreased in plants from both watering conditions. However, in WD plants a residual NPQ is still present until approximately 40 min after 


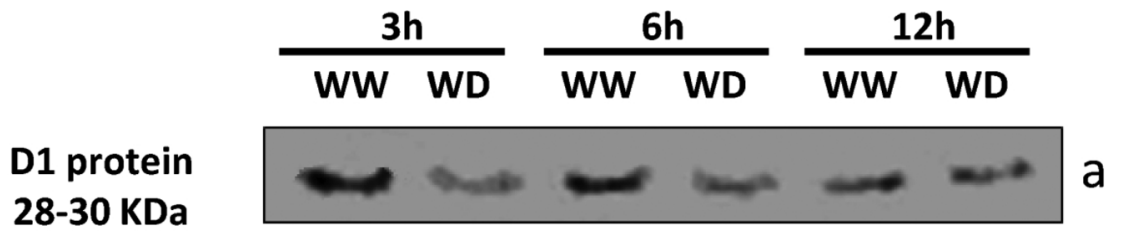

Fig. 3. Changes in photochemical protein abundances in response to the duration of high light (HL) exposure in well-watered (WW) control and water-deficit (WD)-acclimated cashew plants. (A) D1 and (B) plastocyanin. The plants were exposed to $2000 \mu \mathrm{mol} \mathrm{m}-2$ s-1 PPFD for different lengths of time ( 3,6 and $12 \mathrm{~h})$. The blots are representative of four independent replicates.

\section{Plastocyanin 14-19 KDa}

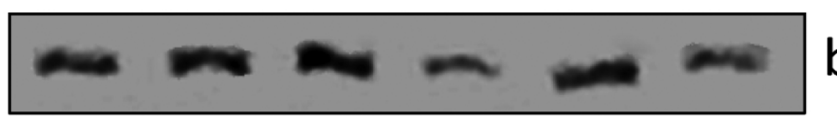

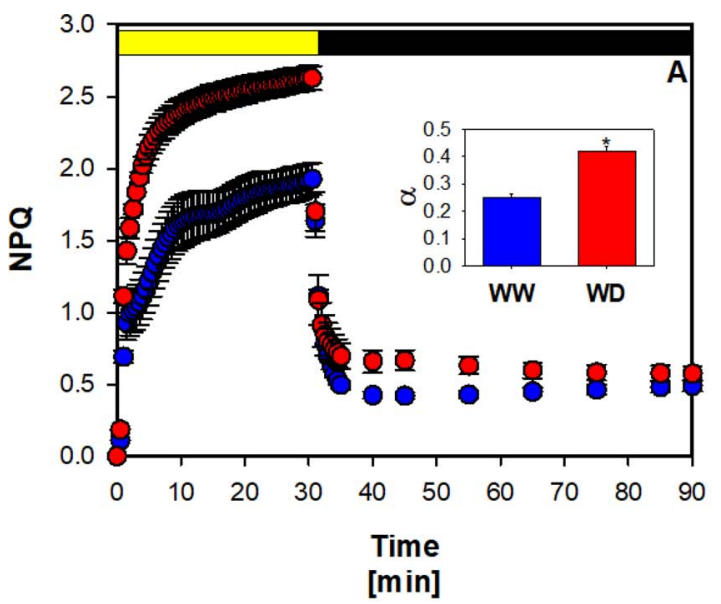

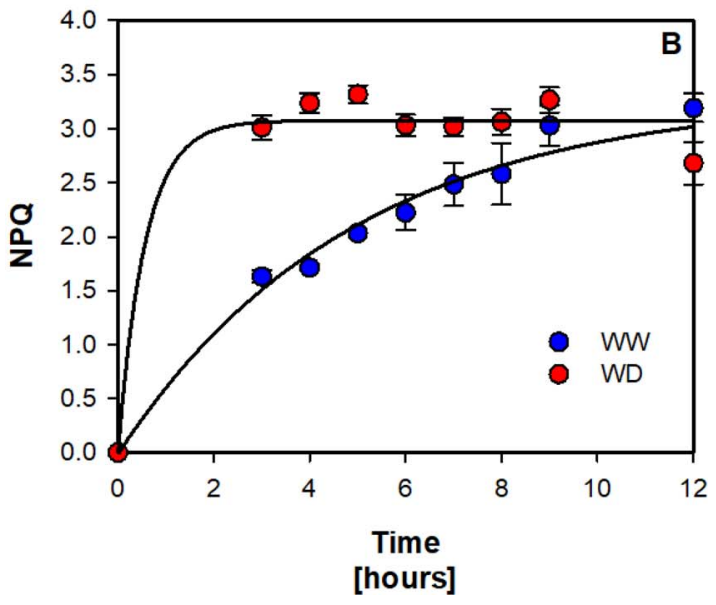

Fig. 4. Short- and long-term kinetics of non-photochemical quenching (NPQ) measured in leaves from cashew plants exposed to different watering conditions, well-watered (WW, blue circles) and water-deficit (WD, red circles) for 21 days. (A) Short-term kinetics were measured on leaves by exposition to actinic light $\left(2000 \mu \mathrm{mol} \mathrm{m}^{-2} \mathrm{~s}^{-1}\right)$ for $30 \mathrm{~min}$, followed by dark relaxation for $1 \mathrm{~h}$. (B) Long-term kinetics were measured on leaves by whole plant exposition to constant $\mathrm{HL}\left(2000 \mu \mathrm{mol} \mathrm{m}^{-2} \mathrm{~s}^{-1}\right)$ and determinations were performed at $3,4,5,6,7,8,9$ and $12 \mathrm{~h}$ after pre-dawn. Circles are average of three independent measurements performed in independent plants $(n=3)$ and bars represent the standard error. (For interpretation of the references to colour in this figure legend, the reader is referred to the web version of this article.)

dark, which is approximately 50\% higher than WW plants (Fig. 4A). After $1 \mathrm{~h}$ of dark recovery WD and WW plants displayed no differences in NPQ values (Fig. 4A). On other hand, the long-term HL experiment revealed that WD plants are capable of inducing NPQ more rapidly compared to WW plants (Fig. 4B). After $3 \mathrm{~h}$ of HL exposure WD plants reached maximum NPQ capacities, whereas WW plants exhibited a gradual induction, reaching maximum values after $8 \mathrm{~h}$ of HL exposure (Fig. 4B). Interestingly, after $12 \mathrm{~h}$ of high light exposure, WD plants exhibited a trend for decrease in NPQ, which was not displayed by WW plants (Fig. 4B).
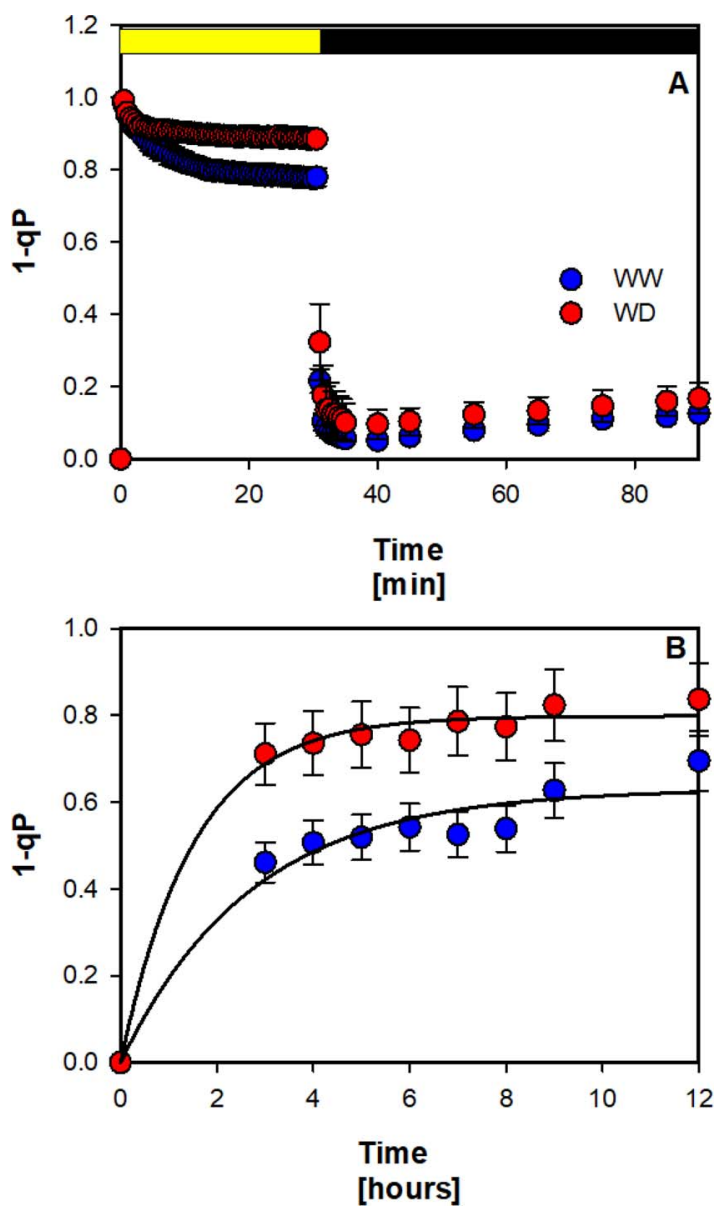

Fig. 5. Short- and long-term kinetics of plastohidroquinone reduced state (1-qP) measured in leaves from cashew plants exposed to different watering conditions, well-watered (WW, blue circles) and water-deficit (WD, red circles) for 21 days. (A) Short-term kinetics were measured on leaves by exposition to actinic light $\left(2000 \mu \mathrm{mol} \mathrm{m}^{-2} \mathrm{~s}^{-1}\right)$ for $30 \mathrm{~min}$, followed by dark relaxation for $1 \mathrm{~h}$. (B) Long-term kinetics were measured on leaves by whole plant exposition to constant $\mathrm{HL}\left(2000 \mu \mathrm{mol} \mathrm{m}^{-2} \mathrm{~s}^{-1}\right)$ and determinations were performed at $3,4,5,6,7,8,9$ and 12 after pre-dawn. Circles are average of three independent measurements performed in independent plants $(n=3)$ and bars represent the standard error. (For interpretation of the references to colour in this figure legend, the reader is referred to the web version of this article.)

\subsection{WD plants exhibit a more reduced state of the plastoquinone pool as compared to $W W$ plants}

Besides WD plants having triggered an effective decrease in PSII activity in combination with strong NPQ induction, they exhibited a more reduced state of plastoquinones (as indicated by the parameter 1qP) when exposed to HL, compared to WW plants (Fig. 5). After 30 min of exposure to HL, WW plants exhibited a reduced state of plastoquinones equal to $80 \%$, whereas WD plants reached a percentage equals to $90 \%$ (Fig. 5A), indicating that RCII was possibly more photoinactived in WD plants than it was in WW leaves. After the dark recovery $(1 \mathrm{~h})$, both 


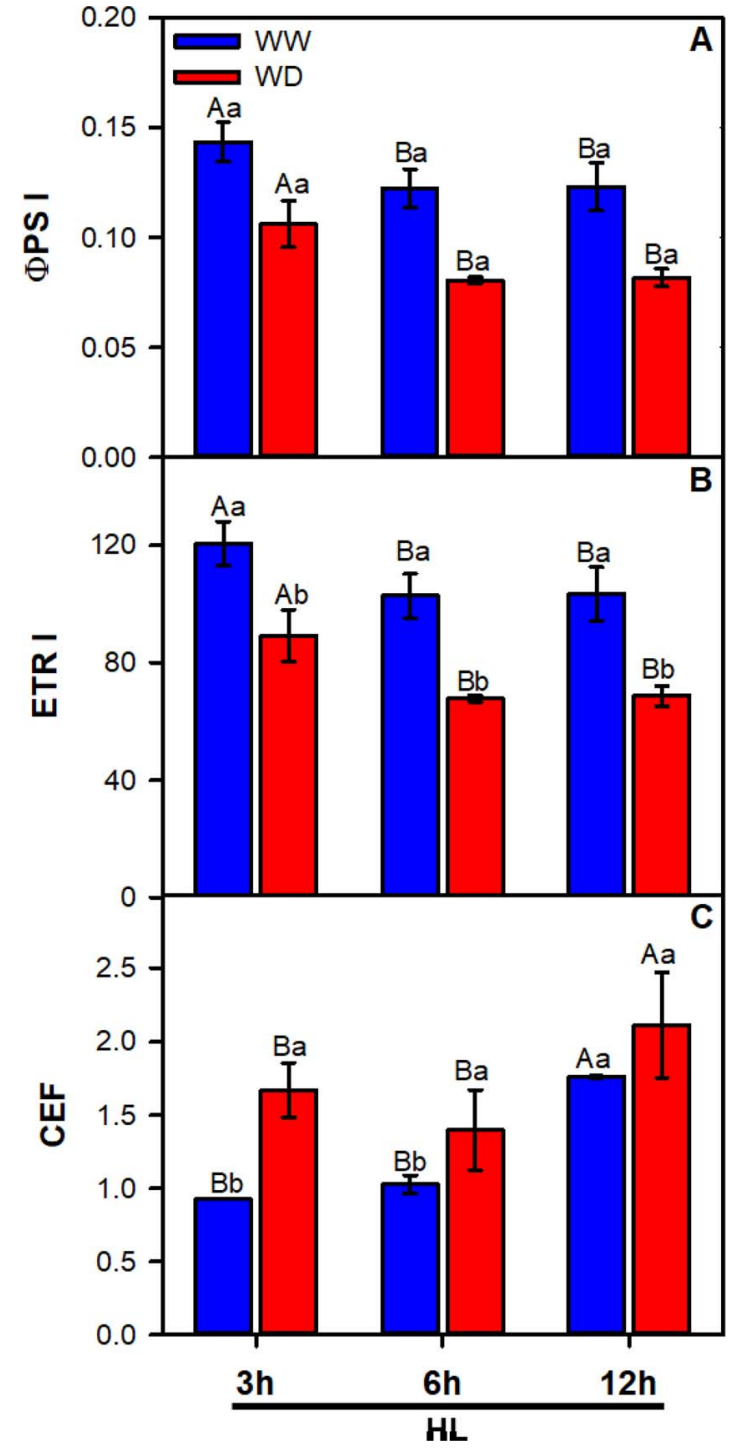

Fig. 6. Changes in PSI parameters in response to time of high light (HL) exposure in wellwatered (WW; blue bars) and water-deficit (WD; red bars)-acclimated cashew plants. (A) actual quantum efficiency from PSI (ФPSI); (B) electron transport rate from PSI (ETRI); (C) cyclic electron flux estimative (CEF; ETRI/ETRII). The plants were exposed to $2000 \mu \mathrm{mol} \mathrm{m}^{-2} \mathrm{~s}^{-1}$ PPFD for different lengths of time (3, 6 and $12 \mathrm{~h}$ ). The values are the means of four replicates, and the letters indicate comparisons using Tukey's test. Capital letters represent differences between treatments within each light duration, and lowercase letters indicate differences between light exposure times within each treatment. Bars represent standard deviation (SD). (For interpretation of the references to colour in this figure legend, the reader is referred to the web version of this article.)

WW and WD plants displayed similar reduced state of plastoquinones (Fig. 5A). The long-term exposure of whole plants to HL corroborated these results, evidencing that WD plants are susceptible to suffer greater over-reduction of plastoquinone pool in response to $\mathrm{HL}$, as compared to WW plants and in WD plants this over reduction occurred faster than in WW plants (Fig. 5B).

3.5. WD cashew plants are capable of triggering a greater decrease in PSI efficiency and inducing cyclic electron flux around PSI

In order to investigate the contribution of PSI to the photoprotective mechanism triggered by cashew plants exposed to combined drought and HL, the absorbance of $\mathrm{P} 700^{+}$was determined (Fig. 6). WD-acclimated plants displayed negative regulation in the actual quantum efficiency at PSI level (ФPSI) and electron transport rate from PSI (ETRI) after $3 \mathrm{~h}, 6 \mathrm{~h}$ and $12 \mathrm{~h}$ of $\mathrm{HL}$ exposure compared to WW cashew

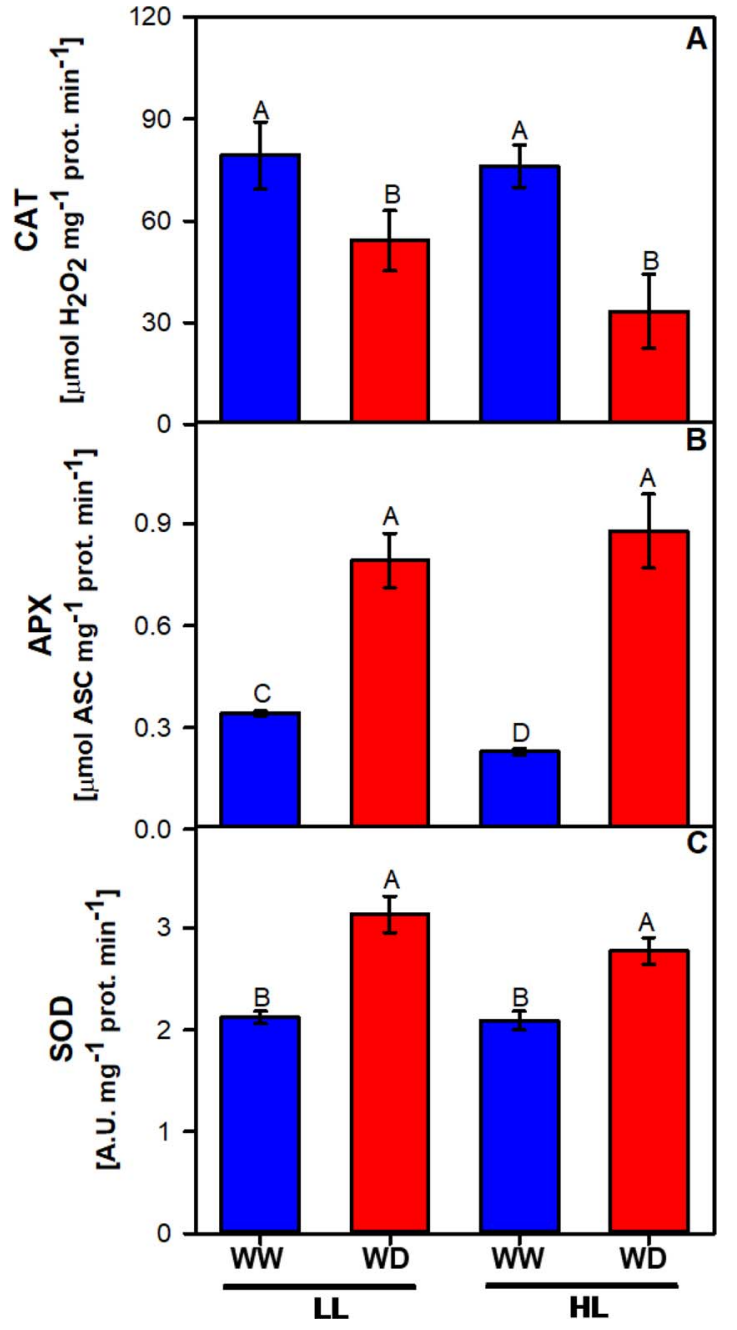

Fig. 7. Changes in activity of antioxidant enzymes in response to different treatments: WW + LL (control), WD + LL, WW + HL and WD + HL. (A) CAT activity; (B) APX activity and (C) SOD activity. The plants were exposed for $12 \mathrm{~h}$ to $\mathrm{LL}\left(200 \mu \mathrm{mol} \mathrm{m}{ }^{-2} \mathrm{~s}^{-1}\right.$ PPFD) or HL ( $2000 \mu \mathrm{mol} \mathrm{m}^{-2} \mathrm{~s}^{-1}$ PPFD). The values are the means of four replicates, and the letters indicate comparisons using Tukey's test. Bars represent standard deviation (SD). Capital letters represent differences between treatments.

(Fig. 6A-B). During HL, the cyclic electron flux (CEF), estimated from the ETRII/ETRI ratios, was more intensely triggered by WD cashew plants, as compared to WW plants (Fig. 6C). WD plants exhibited $60 \%$ higher CEF at $3 \mathrm{~h}$ of $\mathrm{HL}$, as compared to WW plants (Fig. 6C). The differences in CEF displayed by WW- and WD-plants decreased progressively from $3 \mathrm{~h}$ to $12 \mathrm{~h}$ of HL exposure. No significantly differences were detected in CEF from WW and WD plants at $12 \mathrm{~h}$ of HL exposure (Fig. 6C).

\subsection{WD-acclimated plants sustained enzymatic and non-enzymatic antioxidant activities and displayed low ROS accumulation}

In this experiment, plants were exposed to low light intensity - LL $\left(200 \mu \mathrm{mol} \mathrm{m} \mathrm{m}^{-2} \mathrm{~s}^{-1}\right)$ and high light intensity - HL $\left(2000 \mu \mathrm{mol} \mathrm{m} \mathrm{m}^{-2} \mathrm{~s}^{-1}\right)$ for $12 \mathrm{~h}$ in order to compare the performance of WD and WW cashew in terms of antioxidant defense and ROS accumulation. CAT activity was significantly decreased by WD regardless of the light regime and it was not affected by HL in WW plants (Fig. 7A). In contrast, APX activity was strongly increased by WD as in LL as well as in HL (Fig. 7B), whereas the SOD activity displayed a trend similar to APX, being enhanced in WD plants (Fig. 7C). All three enzymes were not affected by HL, regardless of the water regimes. 


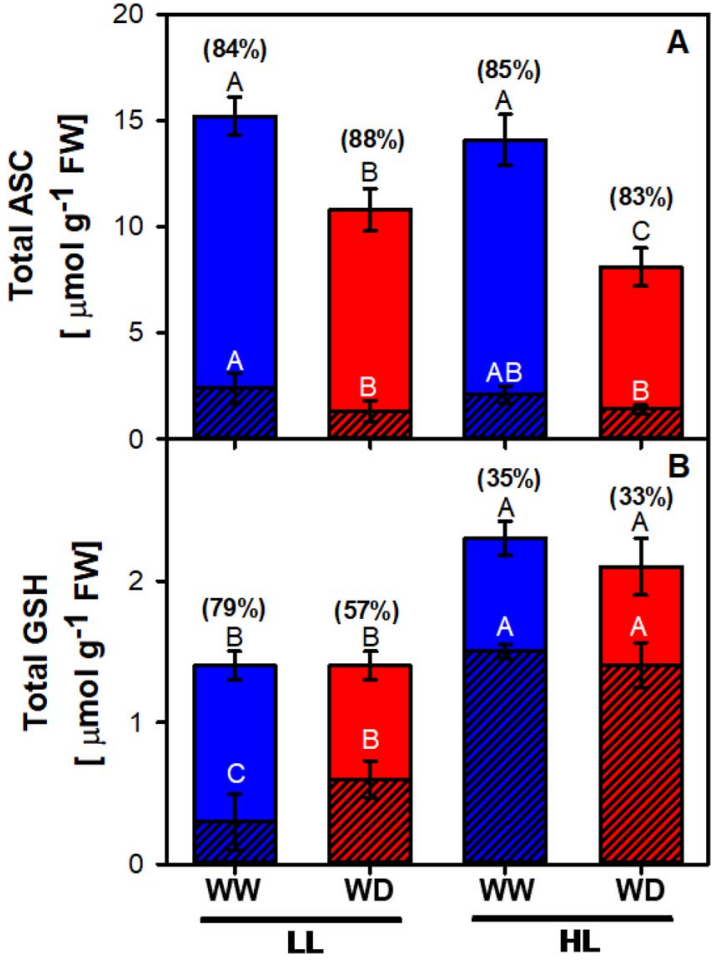

Fig. 8. Changes non-enzymatic antioxidants in response to different treatments: $\mathrm{WW}+\mathrm{LL}$ (control), WD + LL, WW + HL and WD + HL. (A) Reduced ascorbate (ASC; white bars) and oxidized ascorbate (DHA; black bars). (B) Reduced glutathione (GSH; white bars) and oxidized glutathione (GSSG; black bars). The plants were exposed for $12 \mathrm{~h}$ to LL $\left(200 \mu \mathrm{mol} \mathrm{m}^{-2} \mathrm{~s}^{-1}\right.$ PPFD) or HL $\left(2000 \mu \mathrm{mol} \mathrm{m}^{-2} \mathrm{~s}^{-1}\right.$ PPFD). The values are the means of four replicates, and the letters indicate comparisons using Tukey's test. Bars represent standard deviation (SD). Capital letters represent differences between treatments. Values inside brackets represent redox state of ascorbate and glutathione, respectively.

In order to investigate the importance of non-enzymatic antioxidant defense in both WD and WW plants exposed to LL and HL, the contents of ASC, DHA, GSH, GSSG and their respective redox states were measured in leaves after $12 \mathrm{~h}$ of light exposition. Single WD under LL induced a significant decrease in total ASC content (29\%) and the decline was accentuated in HL by a further $25 \%$, all compared to WW + LL (Fig. 8A). Water deficit induced a proportional decrease in the DHA content and as consequence the ASC redox state remained practically unchanged by the effect of drought in both light regimes. The WW plants did not alter their total ASC and DHA contents by the effect of light intensity (Fig. 8A). Differently from ASC, total GSH content strongly increased in both WD and WW plants under HL by $63 \%$ compared to LL (Fig. 8B). Water deficit decreased GSH redox state and this effect was strongly stimulated by HL (from $57 \%$ to $33 \%$ ) compared to $\mathrm{WW}+\mathrm{LL}(79 \%)$. HL also induced drastic reduction in GSH redox state of WW plants compared to LL (from 79\% to 35\%) - (Fig. 8B).

The WD-plants showed lower $\mathrm{H}_{2} \mathrm{O}_{2}$ accumulation indicated by the chemical method as well as by in situ dyeing with $\mathrm{DAB}$, in both light regimes, compared to WW plants (Fig. 9A, B). In presence of HL water deficit-plants displayed lower lipid peroxidation (TBARS content), compared to WW plants (Fig. 9C), indicating that combined drought + HL was favorable to avoid oxidative stress in cashew plants. The absence of oxidative stress in these plants was corroborated by absence of leaf membrane damage (electrolyte leakage), which was low and similar to WW plants (Fig. S2A). The lack of oxidative stress in WD plants was related to a good hydration status in leaves, indicated by high and unchanged relative water content value, which was similar to WW plants (Fig. S2B).
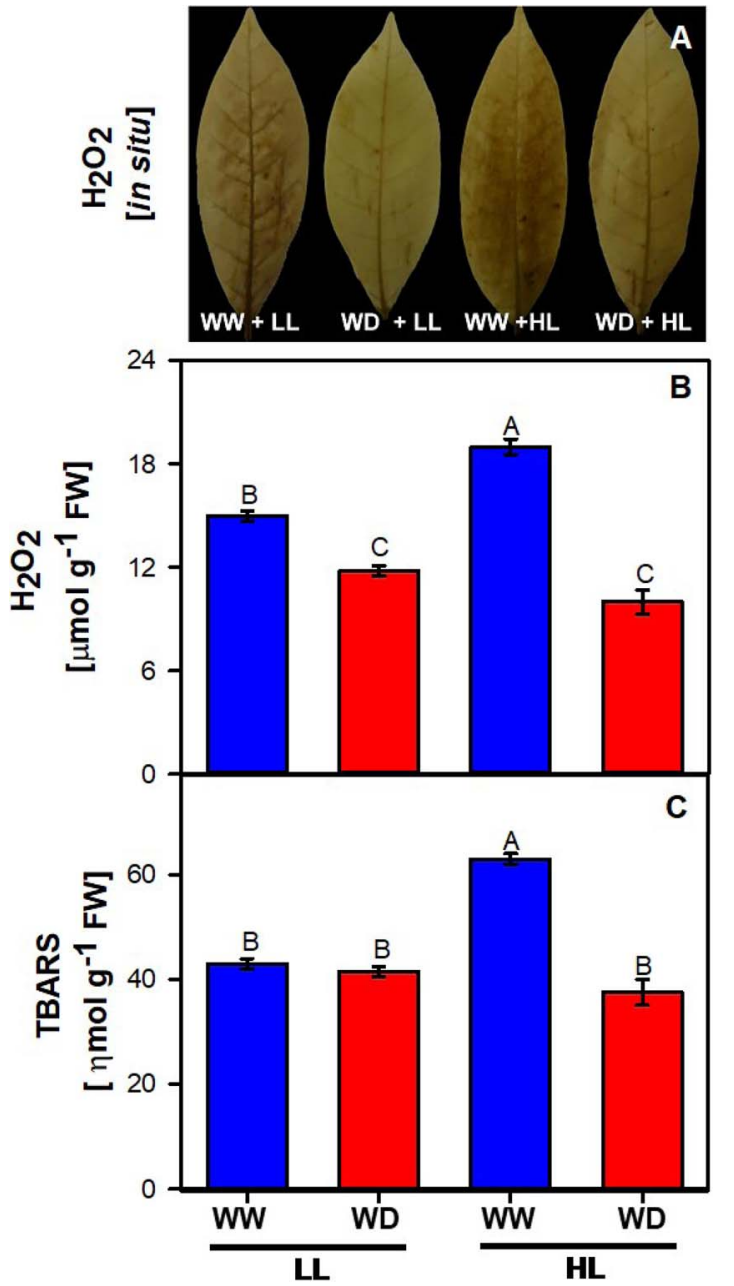

Fig. 9. Changes in oxidative indicators in response to different treatments: $W W+\mathrm{LL}$ (control), WD + LL, WW + HL and WD + HL. (A) In situ $\mathrm{H}_{2} \mathrm{O}_{2}$ accumulation; (B) $\mathrm{H}_{2} \mathrm{O}_{2}$ content and (C) lipid peroxidation (TBARS). The plants were exposed for $12 \mathrm{~h}$ to LL $\left(200 \mu \mathrm{mol} \mathrm{m} \mathrm{m}^{-2} \mathrm{~s}^{-1}\right.$ PPFD) or HL $\left(2000 \mu \mathrm{mol} \mathrm{m} \mathrm{m}^{-2} \mathrm{~s}^{-1}\right.$ PPFD). The values are the means of four replicates, and the letters indicate comparisons using Tukey's test. Bars represent standard deviation (SD).

\subsection{WD-acclimated cashew subjected to HL presented better water use efficiency}

WD plants exposed to both light regimes displayed strong decreases in net photosynthesis $\left(\mathrm{P}_{N}\right)$, stomatal conductance $\left(\mathrm{g}_{\mathrm{s}}\right)$ and increases in water use efficiency (WUE). Surprisingly, WD-treated plants under HL showed increased $\mathrm{P}_{\mathrm{N}}$ compared to WD + LL plants (Fig. 10A). In parallel, stomatal conductance was strongly decreased by WD under LL compared with all other treatments (Fig. 10B). HL induced a decrease in $\mathrm{g}_{\mathrm{s}}$ in WW plants compared to WW + LL (control) and WD plants showed higher WUE compared with all other treatments (Fig. 10C).

\section{Discussion}

The obtained results evidence that cashew is a species tolerant to extreme conditions of combined stress of drought and high light, which is expected since it is extensively cultivated in tropical semiarid regions (Bezerra et al., 2007). Noticeably, in this study the cashew young plants exhibited an effective strategy to cope with water deficit for 21 days, triggering a fast and effective stomatal closure and maintaining of leaf turgor. These results are in accordance with Matos et al. (2003), which reported that drought stressed cashew plants were able to maintaining a good water status in leaves associated with decreased growth. Indeed, 


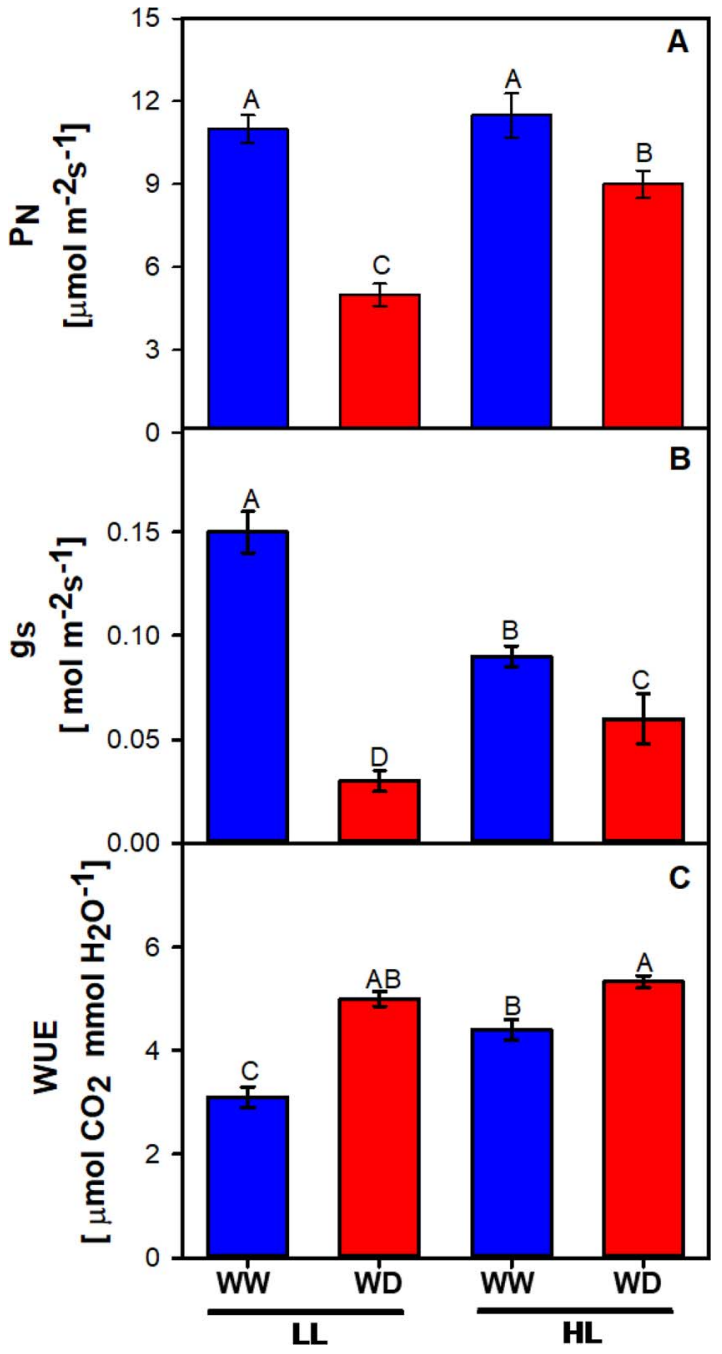

Fig. 10. Changes in gas-exchange parameters in response to different treatments: WW + LL (control), WD + LL, WW + HL and WD + HL. (A) Net photosynthesis, PN; (B) stomatal conductance, gs; and (C) water use efficiency, WUE. The plants were exposed for $12 \mathrm{~h}$ to LL $\left(200 \mu \mathrm{mol} \mathrm{m}{ }^{-2} \mathrm{~s}^{-1}\right.$ PPFD) or HL $\left(2000 \mu \mathrm{mol} \mathrm{m}^{-2} \mathrm{~s}^{-1}\right.$ PPFD). The values are the means of four replicates, and the letters indicate comparisons using Tukey's test. Bars represent standard deviation (SD).

despite the great severity of water restriction followed by HL imposed in this current study, cashew plants did not display stress symptoms as indicated by the unchanged levels of RWC, membrane integrity and lipid peroxidation in leaves.

We have previously reported that cashew plants are tolerant to high salinity under normal temperature (Ferreira-Silva et al., 2011, 2010, 2008; Silveira et al., 2003) Interestingly, cashew plants exposed to high temperature triggers an antioxidant protective mechanism that mitigates the negative effects induced by salt stress (Ferreira-Silva et al., 2012). Despite salt stressed-cashew plants have accumulated significant amount of proline in leaves, this response was a consequence of metabolic disturbance, not contributing for osmotic adjustment (da Rocha et al., 2012). Indeed, cashew leaves are not able to display osmotic adjustment in response to salt stress (Ferreira-Silva et al., 2008). Current studies carried out in our lab have revealed that young cashew plants are not capable to exhibit osmotic adjustment in both leaves and roots in response to prolonged water deficit in substrate (unpublished data).

An important challenge for plants to cope effectively with an abiotic stress such as water deficit and high light is the maintenance of a suitable balance involving light capture and photosynthetic electron consumption by metabolic processes, especially $\mathrm{CO}_{2}$ assimilation and photorespiration (Foyer et al., 2012; Silveira and Carvalho, 2016). This equilibrium is crucial to avoid excess energy and overproduction of ROS in chloroplasts (Duarte et al., 2013; Foyer et al., 2012). However, when ROS are accumulated at low levels in plant cells, they might act as cellular signaling commonly related to the regulation of genes associated with abiotic stress defense responses (Exposito-Rodriguez et al., 2017; Foyer et al., 2017). Otherwise, if the plant fails to maintain the ROS at adequate concentrations, the oxidative stress might be established, inducing severe metabolic disturbances (Maruta et al., 2012; Møller et al., 2007; Naranjo et al., 2016).

A very important aspect of ROS accumulation in thylakoids is its contribution to the photoinhibition process (Nishiyama et al., 2011). Under oxidative stress conditions, excessive ROS is believed to act as a direct inhibitor of elongation factor $\mathrm{G}$ protein, which is essential for protein translation in chloroplasts (Kojima et al., 2007). Thus, excess ROS could cause direct photodamage of RCII proteins (Kato et al., 2015), or alternatively it could lead to the impairment of PSII protein turnover, resulting in photoinhibition (Nishiyama et al., 2011). In the current study cashew plants did not suffer any symptom of oxidative stress and photoinhibition when exposed to a prolonged drought (21 days), followed or not by exposure to HL. Consequently, an important question that could be raised here is: how are cashews able to perform so remarkably?

The data concerning the PSII and PSI activities clearly evidences that cashew plants are able to decrease the linear photosynthetic electron flux in thylakoid membranes when plants were exposed to drought combined with HL. This mechanism is corroborated by the fact that D1 protein in WD plants exposed to HL is significantly less abundant in comparison to WW plants, therefore indicating an active biochemical regulation of the RCII components (Aro et al., 1993). This notable feature could allow a lower input of electron flux under a very high excess energy condition, performing a dynamic and protective photoinhibition (Foyer et al., 2017). This mechanism was probably essential for the mitigation of ROS accumulation in cashew leaves.

That cashew performance is commonly reported for evergreen plants adapted to arid regions, which are able to survive and grow under extreme environmental conditions (Adams et al., 2013, 2006; Baker and Rosenqvist, 2004; Blaikie and Chacko, 1998; Demmig-Adams et al., 2017, 2015). However, despite the strong decrease in photochemical activity during illumination, WD cashew leaves displayed a prominent capability of PSII recovery in the dark, reaching PSII quantum efficiency very similar to WW plants after only a few minutes. To the best of our knowledge, this observation is unprecedented in literature and creates prospects for the existence of a PSII repair mechanism that could have been triggered more effectively in drought treated cashew leaves than in well-watered plants.

These responses displayed by drought-exposed cashew leaves might suggest that this plant species is evolutionarily well adapted to cope with the combination of drought and HL and able to employ unusual photosynthetic mechanisms. How could WD cashew plants be more effective in PSII dark recovery than WW plants and what are the involved physiological implications? In order to answer this question, kinetics of induction and relaxation of NPQ were performed. Several previous reports have evidenced that evergreen plants, such as cashew, when exposed to severe abiotic stress conditions like drought and HL, are able to induce very high NPQ levels. The possibility of PSII antennas of evergreen plants to persist in the quenched state even after long periods of dark recovery, is commonly reported as an important photoprotective mechanism (Demmig-Adams et al., 2017, 2015; Foyer et al., 2017).

Our data showed that drought-exposed cashew leaves displayed a fast increase in NPQ after exposure to HL clearly evidencing that the $\mathrm{qE}$ component is very important for heat dissipation in this plant species. The main NPQ photoprotective component, $\mathrm{qE}$, is induced in the order of few minutes and is dependent on the $\Delta \mathrm{pH}$ formation between the thylakoid lumen and stroma (Ruban et al., 2007); the PsbS protein 
amount (Funk et al., 1995; Niyogi et al., 2005) and the enzymatic activity of violaxanthin deepoxidase (Demmig-Adams, 1990). Our data provide evidences that WD leaves exposed to HL for $3 \mathrm{~h}$ exhibited a strong increase in cyclic electron flux (CEF), which has coincided with the high initial induction of NPQ. After $12 \mathrm{~h}$ of HL exposure, when NPQ in WD and WW plants did not differ, CEF was also similar in leaves from both treatments. Therefore, our data suggest that the CEF was related to NPQ induction in WD leaves exposed to combined HL.

NPQ is a biophysical process that competes directly with PSII quantum efficiency. Thus, since WD cashew plants are able to induce a more effective recovery in PSII quantum efficiency than WW plants, it could be plausible to argue that NPQ relaxation mechanisms in drought-leaves would be more efficient than in WW ones. Indeed, a faster NPQ relaxation could imply a more effective utilization of energy for photochemical processes (Kromdijk et al., 2016). However, our data clearly show that WD cashew leaves displayed a slight delay in NPQ dark relaxation after HL exposure, in comparison to WW plants. This response evidences that drought-treated leaves exhibited a quenched state as expected for an evergreen species, probably associated to qZ component of the NPQ (Jahns and Holzwarth, 2012; Nilkens et al., 2010).

Another explanation for a possible increased capability of PSII quantum recovery in the dark, displayed by WD cashew leaves could be linked to the D1 protein turnover process. As excess ROS is believed to generate a strong delay in this process (Nishiyama et al., 2011), the fact that cashew leaves have displayed a very effective ROS scavenging, associated with decreased ROS production by photochemical mechanisms, these features could, together, have contributed to a more efficient PSII reaction center repair in the dark. Indeed, WD cashew leaves exhibited a remarked increase in SOD and APX activities in parallel to reduced $\mathrm{H}_{2} \mathrm{O}_{2}$ and TBARS accumulation. In addition, these plants displayed a great GSH consumption (oxidation) associated to increase in ASC synthesis. Together, these antioxidant responses should have been crucial for ROS scavenging (Foyer et al., 2012; Noctor et al., 2014).

Under HL stress, the redox state of the plastoquinone pool is believed to act as an important retrograde signal from chloroplasts to nucleus (Allen, 1993; Allen et al., 2011; Puthiyaveetil et al., 2012). As reported previously, the regulation of the expression of several important proteins for abiotic stress defense is related to signaling transduction pathway originated from plastoquinone pool redox state (Allen et al., 2011; Karpinski et al., 1997; Pfannschmidt et al., 2001). Indeed, the expression of cytosolic APX isoforms, which are important enzymes involved in $\mathrm{H}_{2} \mathrm{O}_{2}$ scavenging, are strongly induced by $\mathrm{HL}$ and the signaling process related to such induction is dependent on plastoquinone pool reduced state (Karpinski et al., 1997). Therefore, the remarkable increase in APX activity, exhibited by WD cashew leaves, could have been related to a retrograde signaling process. In this case, the signaling transduction pathway could have been originated from a higher reduced state related to plastoquinone pool in response to HL (as indicated by 1-qP changes). Nonetheless, further research is still need to the effective elucidation of the molecular mechanism related to chloroplast retrograde signaling for antioxidant protection in WD cashew leaves.

Another important feature that could be closely related to enhanced antioxidant machinery displayed by WD cashew leaves is the control of stomatal aperture. The stomatal closure is an important regulatory mechanism for photosynthetic efficiency under drought conditions and it is directly affected by the levels of accumulated intracellular ROS (Chen and Gallie, 2004). Our data clearly shows that WD plants are able to maintain a more favorable stomatal conductance in presence of $\mathrm{HL}$ than in presence of LL. Therefore, under such conditions a higher $\mathrm{CO}_{2}$ assimilation by the Calvin-Benson cycle should have contributed to lower reducing power accumulation in thylakoids, which inevitably leads to a lower ROS accumulation in chloroplasts (Foyer et al., 2012), generating a virtuous cycle to the whole photosynthetic capacity.

Fig. 11 presents an integrative and schematic view of the main

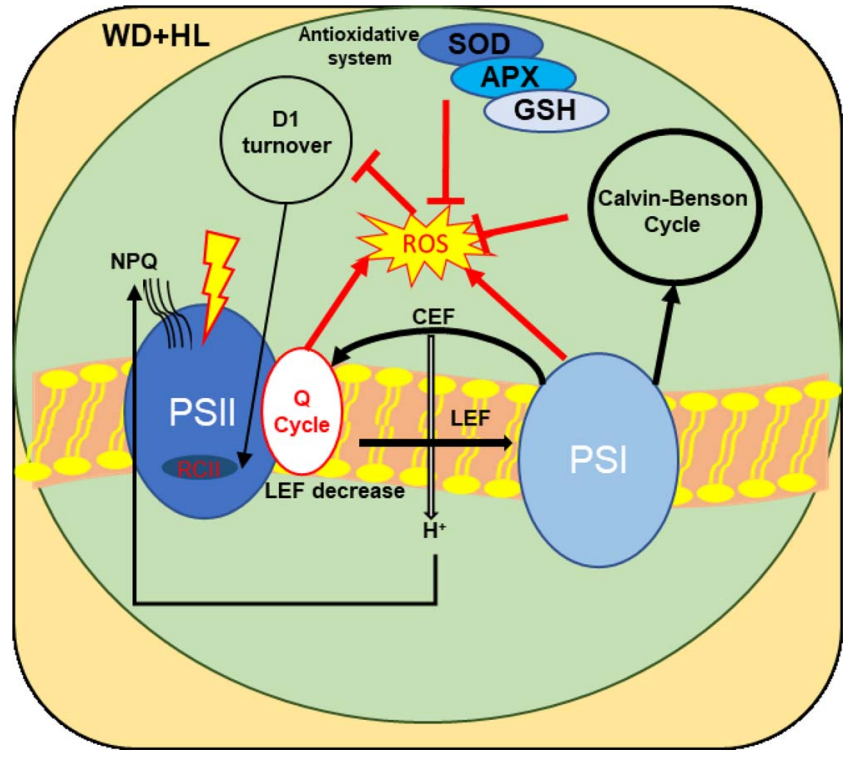

Fig. 11. A simplified model showing the most important photosynthetic and antioxidant mechanisms triggered by cashew plants exposed to drought combined with high light. The model highlights the coordinated actions involving several processes. The ROS accumulation during $\mathrm{HL}$ is avoided by a combination of decreased in linear electron flux (including D1 protein regulation) and effective antioxidant machinery involving APX, SOD and GSH. In addition, the increase in CEF might have been associated with the strong NPQ induction, especially at $3 \mathrm{~h}$ of HL exposure. In parallel to the photochemical and antioxidant adjustments the maintenance of the Calvin-Benson cycle activity should have contributed to excess reducing power dissipation in chloroplasts. During the post-HL dark recovery, the low levels of ROS accumulated might have contributed to the effective restauration of RCII system in WD plants, reaching similar Fv/Fm levels to WW plants.

features displayed by cashew plants exposed to water deficit followed by high light. The model highlights the antioxidant protection, ROS accumulation and photochemical regulation. A central point that emerges from our study is what is the physiological and evolutionary significance for a faster dark recovery of the PSII in WD cashew? Additionally, it is important also to elucidate the underlying mechanisms involved in the decrease of PSII and PSI activities in drought-exposed cashew leaves exposed to high light. In addition, further studies are required to determine the molecular mechanism behind the interactions involving plastoquinone reduced state, antioxidative signaling and PSII recovery in WD cashew plants.

\section{Conclusion}

We presented clear evidence that cashew plants exposed to drought display an intense decrease in PSII and PSI activities, associated with a great induction in thermal energy dissipation (qE). Despite the decrease in PSII quantum efficiency, WD cashew leaves can rapidly recover PSII activity during the dark, indicating that RCII repair mechanisms could be very effective in such plants. The induction of active antioxidant machinery, involving SOD, APX and GSH, might have contributed to enhance the PSII recovery efficiency during darkness. These findings are unprecedented in literature and provide an important piece in the puzzle of comprehension on how plants can survive under extreme abiotic stress conditions.

\section{Conflict of interest}

None declared.

\section{Funding}

The authors are grateful to Coordination for the Improvement of Higher Education Personnel (Coordenação de Aperfeiçoamento de 
Pessoal de Nível Superior - CAPES), National Council for Scientific and Technological Development (Conselho Nacional de Desenvolvimento Científico e Tecnológico - CNPq) - Proc. 460212/2014 and Fundação Cearense de Apoio ao Desenvolvimento Científico e Tecnológico (FUNCAP) for financial support. FELC is supported by FUNCAP/CAPES (Bolsista CAPES/BRASIL - Proc. 88887.162856/2018-00).

\section{Authors contributions}

CSL conducted experiments and performed biochemical measurements; SLF-S conducted experiments, interpreted data and contributed with writing; FELC interpreted data and contributed with writing; MCLN performed photosynthesis measurements; RMA conducted experiments; ENS interpreted data; RJS performed photochemical determinations; JAGS performed manuscript writing and supervised the research.

\section{Acknowledgements}

The authors are thankful to Dr. Max Ware and Professor Danilo Daloso, who gently revised the manuscript text and performed valuable considerations.

\section{Appendix A. Supplementary data}

Supplementary data associated with this article can be found, in the online version, at https://doi.org/10.1016/j.envexpbot.2018.02.001.

\section{References}

Adams, W.W., Zarter, C.R., Mueh, K.E., Amiard, V., Demmig-Adams, B., 2006. Energy dissipation and photoinhibition: a continuum of photoprotection. Photoinhibition, Gene Regul. Environ. pp. 49-64.

Adams, W.W., Muller, O., Cohu, C.M., Demmig-Adams, B., 2013. May photoinhibition be a consequence, rather than a cause, of limited plant productivity? Photosynth. Res. 117, 31-44.

Allen, J.F., Santabarbara, S., Allen, C.A., Puthiyaveetil, S., 2011. Discrete redox signaling pathways regulate photosynthetic light-harvesting and chloroplast gene transcription. PLoS One 6, e26372.

Allen, J.F., 1993. Control of gene expression by redox potential and the requirement for chloroplast and mitochondrial genomes. J. Theor. Biol. 165, 609-631.

Aro, E.M., McCaffery, S., Anderson, J.M., 1993. Photoinhibition and D1 protein degradation in peas acclimated to different growth irradiances. Plant Physiol. 103, 835-843.

Asada, K., 1992. Ascorbate peroxidase - a hydrogen peroxide-scavenging enzyme in plants. Physiol. Plant 85, 235-241.

Baker, N.R., Rosenqvist, E., 2004. Applications of chlorophyll fluorescence can improve crop production strategies: an examination of future possibilities. J. Exp. Bot. 55, $1607-1621$.

Beauchamp, C., Fridovich, I., 1971. Superoxide dismutase: improved assays and an assay applicable to acrylamide gels. Anal. Biochem. 44, 276-287.

Bezerra, M.A., De Lacerda, C.F., Gomes Filho, E., De Abreu, C.E.B., Prisco, J.T., 2007. Physiology of cashew plants grown under adverse conditions. Braz. J. Plant Physiol. 19, 449-461.

Blaikie, S.J., Chacko, E.K., 1998. Sap flow: leaf gas exchange and chlorophyll fluorescence of container-grown cashew (Anacardium occidentale L.) trees subjected to repeated cycles of soil drying. Aust. J. Exp. Agric. 38, 305-311.

Cakmak, I., Horst, W.J., 1991. Effect of aluminium on net efflux of nitrate and potassium from root tips of soybean (Glycine max L.). J. Plant Physiol. 138, 400-403.

Cavalcanti, F.R., Oliveira, J.T.A., Martins-Miranda, A.S., Viégas, R.A., Silveira, J.A.G., 2004. Superoxide dismutase, catalase and peroxidase activities do not confer protection against oxidative damage in salt-stressed cowpea leaves. New Phytol. 163, 563-571.

Cheeseman, J.M., 2006. Hydrogen peroxide concentrations in leaves under natural conditions. J. Exp. Bot. 57, 2435-2444.

Chen, Z., Gallie, D.R., 2004. The ascorbic acid redox state controls guard cell signaling and stomatal movement. Plant Cell 16, 1143-1162.

da Rocha, I.M.A., Vitorello, V.A., Silva, J.S., Ferreira-Silva, S.L., Viégas, R.A., Silva, E.N., Silveira, J.A.G., 2012. Exogenous ornithine is an effective precursor and the $\delta$-ornithine amino transferase pathway contributes to proline accumulation under high $\mathrm{N}$ recycling in salt-stressed cashew leaves. J. Plant Physiol. 169, 41-49.

de Souza, R.P., Ribeiro, R.V., Machado, E.C., Oliveira, R.F., Silveira, J.A.G., 2005. Photosynthetic responses of young cashew plants to varying environmental conditions. Pesqui. Agropecu. Bras. 40, 735-744.

Demmig-Adams, B., Muller, O., Stewart, J.J., Cohu, C.M., Adams, W.W., 2015 Chloroplast thylakoid structure in evergreen leaves employing strong thermal energy dissipation. J. Photochem. Photobiol. B Biol. 152, 357-366.

Demmig-Adams, B., Stewart, J.J., Adams, W.W., 2017. Environmental regulation of intrinsic photosynthetic capacity: an integrated view. Curr. Opin. Plant Biol. 37, 34-41.

Demmig-Adams, B., 1990. Carotenoids and photoprotection in plants: a role for the xanthophyll zeaxanthin. BBA - Bioenergy 1020, 1-24.

Duarte, B., Santos, D., Marques, J.C., Caçador, I., 2013. Ecophysiological adaptations of two halophytes to salt stress: photosynthesis, PS II photochemistry and anti-oxidant feedback - Implications for resilience in climate change. Plant Physiol. Biochem. 67, $178-188$.

Exposito-Rodriguez, M., Laissue, P.P., Yvon-Durocher, G., Smirnoff, N., Mullineaux, P.M., 2017. Photosynthesis-dependent $\mathrm{H}_{2} \mathrm{O}_{2}$ transfer from chloroplasts to nuclei provides a high-light signalling mechanism. Nat. Commun. 8, 4.

Ferreira-Silva, S.L., Silveira, J.A.G., Voigt, E.L., Soares, L.S.P., Viégas, R.A., 2008. Changes in physiological indicators associated with salt tolerance in two contrasting cashew rootstocks. Braz. J. Plant Physiol. 20, 51-59.

Ferreira-Silva, S.L., Silva, E.N., Carvalho, F.E.L., de Lima, C.S., Alves, F.A.L., Silveira, J.A.G., 2010. Physiological alterations modulated by rootstock and scion combination in cashew under salinity. Sci. Hortic. 127, 39-45.

Ferreira-Silva, S.L., Voigt, E.L., Silva, E.N., Maia, J.M., Fontenele de, A.V., Silveira, J.A.G., 2011. High temperature positively modulates oxidative protection in salt-stressed cashew plants. Environ. Exp. Bot. 74, 162-170.

Ferreira-Silva, S.L., Voigt, E.L., Silva, E.N., Maia, J.M., Aragão, T.C.R., Silveira, J.A.G., 2012. Partial oxidative protection by enzymatic and non-enzymatic components in cashew leaves under high salinity. Biol. Plant 56, 172-176.

Finazzi, G., Johnson, G.N., 2016. Cyclic electron flow: facts and hypotheses. Photosynth. Res. 129, 227-230.

Flexas, J., Bota, J., Escalona, J.M., Sampol, B., Medrano, H., 2002. Effects of drought on photosynthesis in grapevines under field conditions: an evaluation of stomatal and mesophyll limitations. Funct. Plant Biol. 29, 461.

Flexas, J., Ribas-Carbó, M., Diaz-Espejo, A., Galmés, J., Medrano, H., 2008. Mesophyll conductance to $\mathrm{CO}_{2}$ Current knowledge and future prospects. Plant Cell Environ. 31, $602-621$.

Flexas, J., Niinemets, Ü., Gallé, A., Barbour, M.M., Centritto, M., Diaz-Espejo, A., Douthe, C., Galmés, J., Ribas-Carbo, M., Rodriguez, P.L., Rosselló, F., Soolanayakanahally, R., Tomas, M., Wright, I.J., Farquhar, G.D., Medrano, H., 2013. Diffusional conductances to $\mathrm{CO}_{2}$ as a target for increasing photosynthesis and photosynthetic water-use efficiency. Photosynth. Res. 117, 45-59.

Foyer, C.H., Neukermans, J., Queval, G., Noctor, G., Harbinson, J., 2012. Photosynthetic control of electron transport and the regulation of gene expression. J. Exp. Bot. 63, 1637-1661.

Foyer, C.H., Ruban, A.V., Noctor, G., 2017. Viewing oxidative stress through the lens of oxidative signalling rather than damage. Biochem. J. 474, 877-883.

Funk, C., Schroëder, W.P., Napiwotzki, A., Tjus, S.E., Renger, G., Andersson, B., 1995. The PS II-S protein of higher plants: a new type of pigment binding protein. Biochemistry 34, 11133-11141.

Galmés, J., Medrano, H., Flexas, J., 2006. Acclimation of Rubisco specificity factor to drought in tobacco: discrepancies between in vitro and in vivo estimations. J. Exp. Bot. 57, 3659-3667.

Galmés, J., Aranjuelo, I., Medrano, H., Flexas, J., 2013. Variation in Rubisco content and activity under variable climatic factors. Photosynth. Res. 117, 73-90.

Giannopolitis, C.N., Ries, S.K., 1977. Superoxide dismutases: II. purification and quantitative relationship with water-soluble protein in seedlings. Plant Physiol. 59, 315-318.

Griffith, O.W., 1980. Determination of glutathione and glutathione disulfide using glutathione reductase and 2-vinylpyridine. Anal. Biochem. 106, 207-212.

Havir, E.A., McHale, N.A., 1987. Biochemical and developmental characterization of multiple forms of catalase in tobacco leaves. Plant Physiol. 84, 450-455.

Jahns, P., Holzwarth, A.R., 2012. The role of the xanthophyll cycle and of lutein in photoprotection of photosystem II. Biochim. Biophys. Acta - Bioenergy 1817, 182-193.

Kampfenkel, K., Vanmontagu, M., Inze, D., 1995. Extraction and determination of ascorbate and dehydroascorbate from plant tissue. Anal. Biochem. 225, 165-167.

Karpinski, S., Escobar, C., Karpinska, B., Creissen, G., Mullineaux, P.M., 1997. Photosynthetic electron transport regulates the expression of cytosolic ascorbate peroxidase genes in arabidopsis during excess light stress. Plant Cell 9, 627-640.

Kato, Y., Ozawa, S.I., Takahashi, Y., Sakamoto, W., 2015. D1 fragmentation in photosystem II repair caused by photo-damage of a two-step model. Photosynth. Res. 126, 409-416.

Klughammer, C., Schreiber, U., 1994. An improved method, using saturating light pulses, for the determination of photosystem I quantum yield via $\mathrm{P} 00^{+}$-absorbance changes at $830 \mathrm{~nm}$. Planta 192, 261-268.

Kojima, K., Oshita, M., Nanjo, Y., Kasai, K., Tozawa, Y., Hayashi, H., Nishiyama, Y., 2007. Oxidation of elongation factor $\mathrm{G}$ inhibits the synthesis of the D1 protein of photosystem II. Mol. Microbiol. 65, 936-947.

Kromdijk, J., Głowacka, K., Leonelli, L., Gabilly, S.T., Iwai, M., Niyogi, K.K., Long, S.P., 2016. Improving photosynthesis and crop productivity by accelerating recovery from photoprotection. Science 354, 857-861.

Labs, M., Rühle, T., Leister, D., 2016. The antimycin A-sensitive pathway of cyclic electron flow: from 1963 to 2015. Photosynth. Res. 129, 231-238.

Lin, C.Y., Trinh, N.N., Fu, S.F., Hsiung, Y.C., Chia, L.C., Lin, C.W., Huang, H.J., 2013. Comparison of early transcriptome responses to copper and cadmium in rice roots. Plant Mol. Biol. 81, 507-522.

Møller, I.M., Jensen, P.E., Hansson, A., 2007. Oxidative modifications to cellular components in plants. Annu. Rev. Plant Biol. 58, 459-481.

Maruta, T., Inoue, T., Noshi, M., Tamoi, M., Yabuta, Y., Yoshimura, K., Ishikawa, T., Shigeoka, S., 2012. Cytosolic ascorbate peroxidase 1 protects organelles against 
oxidative stress by wounding- and jasmonate-induced $\mathrm{H}_{2} \mathrm{O}_{2}$ in Arabidopsis plants. Biochim. Biophys. Acta - Gen. Subj. 1820, 1901-1907.

Matos, N.N., Texeira Junior, A.C., Silveira, J.A.G., 2003. Influence of rootstock on physiologycal behavior of grafted cashew nut tree (Anacardium occidentale 1.) under two stress conditions. Rev. Bras. Frutic. 25, 27-31.

Nakano, Y., Asada, K., 1981. Hydrogen peroxide is scavenged by ascorbated-specific peroxidase in spinach chloroplasts. Plant Cell Physiol. 22, 867-880.

Naranjo, B., Mignée, C., Krieger-Liszkay, A., Hornero-Méndez, D., Gallardo-Guerrero, L., Cejudo, F.J., Lindahl, M., 2016. The chloroplast NADPH thioredoxin reductase C, NTRC, controls non-photochemical quenching of light energy and photosynthetic electron transport in Arabidopsis. Plant Cell Environ. 39, 804-822.

Nilkens, M., Kress, E., Lambrev, P., Miloslavina, Y., Müller, M., Holzwarth, A.R., Jahns, P., 2010. Identification of a slowly inducible zeaxanthin-dependent component of nonphotochemical quenching of chlorophyll fluorescence generated under steady-state conditions in Arabidopsis. Biochim. Biophys. Acta - Bioenergy 1797, 466-475.

Nishiyama, Y., Allakhverdiev, S.I., Murata, N., 2011. Protein synthesis is the primary target of reactive oxygen species in the photoinhibition of photosystem II. Physiol. Plant. 142, 35-46.

Niyogi, K.K., Li, X.P., Rosenberg, V., Jung, H.S., 2005. Is PsbS the site of non-photochemical quenching in photosynthesis? J. Exp. Bot. 56, 375-382.

Noctor, G., Mhamdi, A., Foyer, C.H., 2014. The roles of reactive oxygen metabolism in drought: not so cut and dried. Plant Physiol. 164, 1636-1648.

Pfannschmidt, T., Schütze, K., Brost, M., Oelmüller, R., 2001. A novel mechanism of nuclear photosynthesis gene regulation by redox signals from the chloroplast during photosystem stoichiometry adjustment. J. Biol. Chem. 276, 36125-36130.

Pinheiro, C., Chaves, M.M., 2011. Photosynthesis and drought: can we make metabolic connections from available data? J. Exp. Bot. 62, 869-882.

Puthiyaveetil, S., Ibrahim, I.M., Allen, J.F., 2012. Oxidation-reduction signalling components in regulatory pathways of state transitions and photosystem stoichiometry adjustment in chloroplasts. Plant Cell Environ. 35, 347-359.

Ruban, A.V., Berera, R., Ilioaia, C., van Stokkum, I.H.M., Kennis, J.T.M., Pascal, A.A., van Amerongen, H., Robert, B., Horton, P., van Grondelle, R., 2007. Identification of a mechanism of photoprotective energy dissipation in higher plants. Nature 450,
$575-578$.

Ruban, A.V., 2017. Quantifying the efficiency of photoprotection. Philos. Trans. R. Soc. B Biol. Sci. 372, 20160393.

Schreiber, U., Bilger, W., Neubauer, C., 1995. Chlorophyll fluorescence as a nonintrusive indicator for rapid assessment of In vivo photosynthesis. In: Schulze, E.-D., Caldwell, M.M. (Eds.), Ecophysiology of Photosynthesis. Springer, Berlin Heidelberg, pp. 49-70.

Shigeoka, S., Maruta, T., 2014. Cellular redox regulation, signaling, and stress response in plants. Biosci. Biotechnol. Biochem. 78, 1457-1470.

Silveira, J.A.G., Carvalho, F.E.L., 2016. Proteomics, photosynthesis and salt resistance in crops: an integrative view. J. Proteomics 143, 24-35.

Silveira, J.A.G., Viégas, R.D.A., da Rocha, I.M.A., Moreira, A.C.D.O.M., Moreira, R.D.A., Oliveira, J.T.A., 2003. Proline accumulation and glutamine synthetase activity are increased by salt-induced proteolysis in cashew leaves. J. Plant Physiol. 160, $115-123$.

Suzuki, N., Rivero, R.M., Shulaev, V., Blumwald, E., Mittler, R., 2014. Abiotic and biotic stress combinations. New Phytol. 203, 32-43.

Tikkanen, M., Aro, E.M., 2014. Integrative regulatory network of plant thylakoid energy transduction. Trends Plant Sci. 19, 10-17.

Towbin, H., Staehelin, T., Gordon, J., 1979. Electrophoretic transfer of proteins from polyacrylamide gels to nitrocellulose sheets: procedure and some applications. Proc. Natl. Acad. Sci. U.S.A. 76, 4350-4354.

Yamori, W., Sakata, N., Suzuki, Y., Shikanai, T., Makino, A., 2011. Cyclic electron flow around photosystem I via chloroplast $\mathrm{NAD}(\mathrm{P}) \mathrm{H}$ dehydrogenase (NDH) complex performs a significant physiological role during photosynthesis and plant growth at low temperature in rice. Plant J. 68, 966-976.

Zimmermann, P., Heinlein, C., Orendi, G., Zentgraf, U., 2006. Senescence-specific regulation of catalases in Arabidopsis thaliana (L.) heynh. Plant Cell Environ. 29, 1049-1060.

Zou, J.-J., Li, X.-D., Ratnasekera, D., Wang, C., Liu, W.-X., Song, L.-F., Zhang, W.-Z., Wu, W.-H., 2015. Arabidopsis calcium-dependent protein kinase8 and catalase 3 function in abscisic acid-mediated signaling and $\mathrm{H}_{2} \mathrm{O}_{2}$ homeostasis in stomatal guard cells under drought stress. Plant Cell 27, 1445-1460. 